\title{
Correction to: Design, synthesis and SAR of novel sulfonylurea derivatives for the treatment of diabetes mellitus in rats
}

\author{
Farid M. Sroor $\mathbb{1}^{1} \cdot$ Wahid M. Basyouni ${ }^{1} \cdot$ Hanan F. Aly ${ }^{2}$ Sanaa A. Ali ${ }^{2} \cdot$ Azza F. Arafa $^{2}$
}

Published online: 24 December 2021

(c) Springer Science+Business Media, LLC, part of Springer Nature 2021

Correction to: Medicinal Chemistry Research (2021)

https://doi.org/10.1007/s00044-021-02829-z
In the original publication of the article, Figs. 10 and 11 had typographical. The figures should have appeared as shown below.

The original article has been corrected.

2 Department of Therapeutic Chemistry, National Research Centre, Cairo, Egypt 
Fig. 10
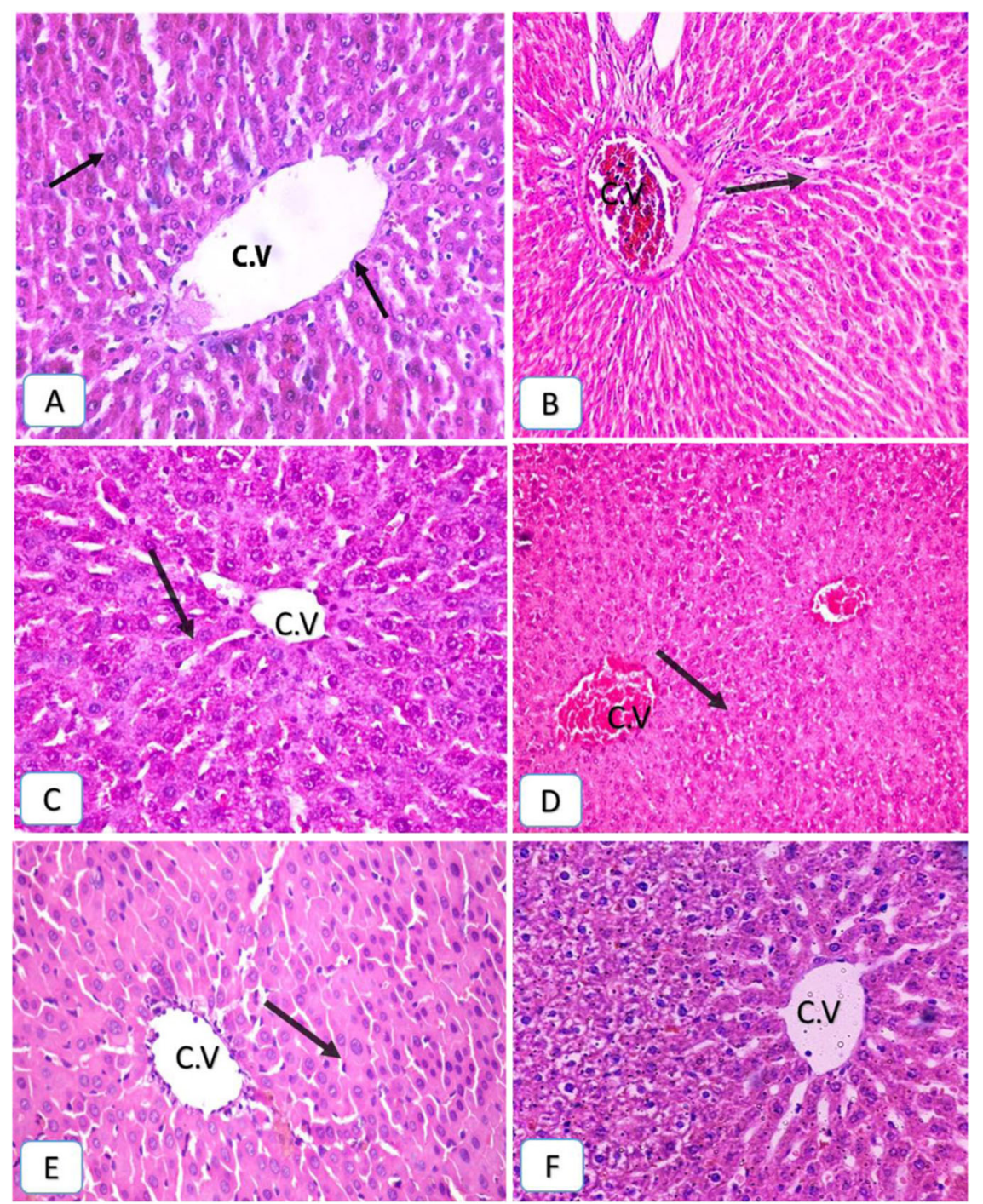
Fig. 11
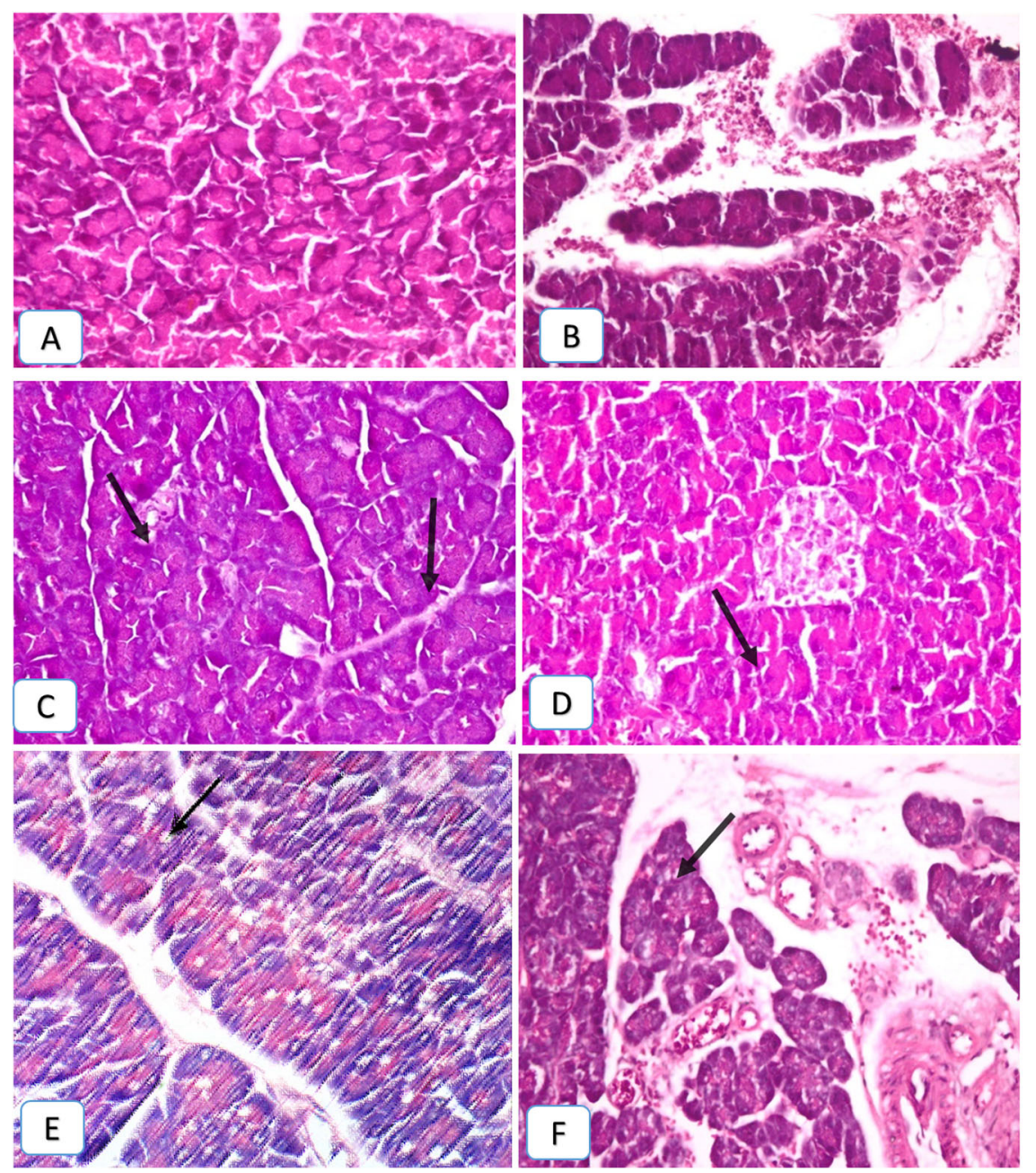